\title{
COMMENT
}

POLICY Research with animals containing human material needs regulation $\mathbf{p . 4 4 8}$
CONSERVATION Declining shark numbers implicate fin hunters p.451
CULTURE Contemporary artists inspired by psychiatric patients $\mathbf{p . 4 5 2}$
FISHERIES European reforms should follow the money and scientific advice $\mathbf{p . 4 5 4}$

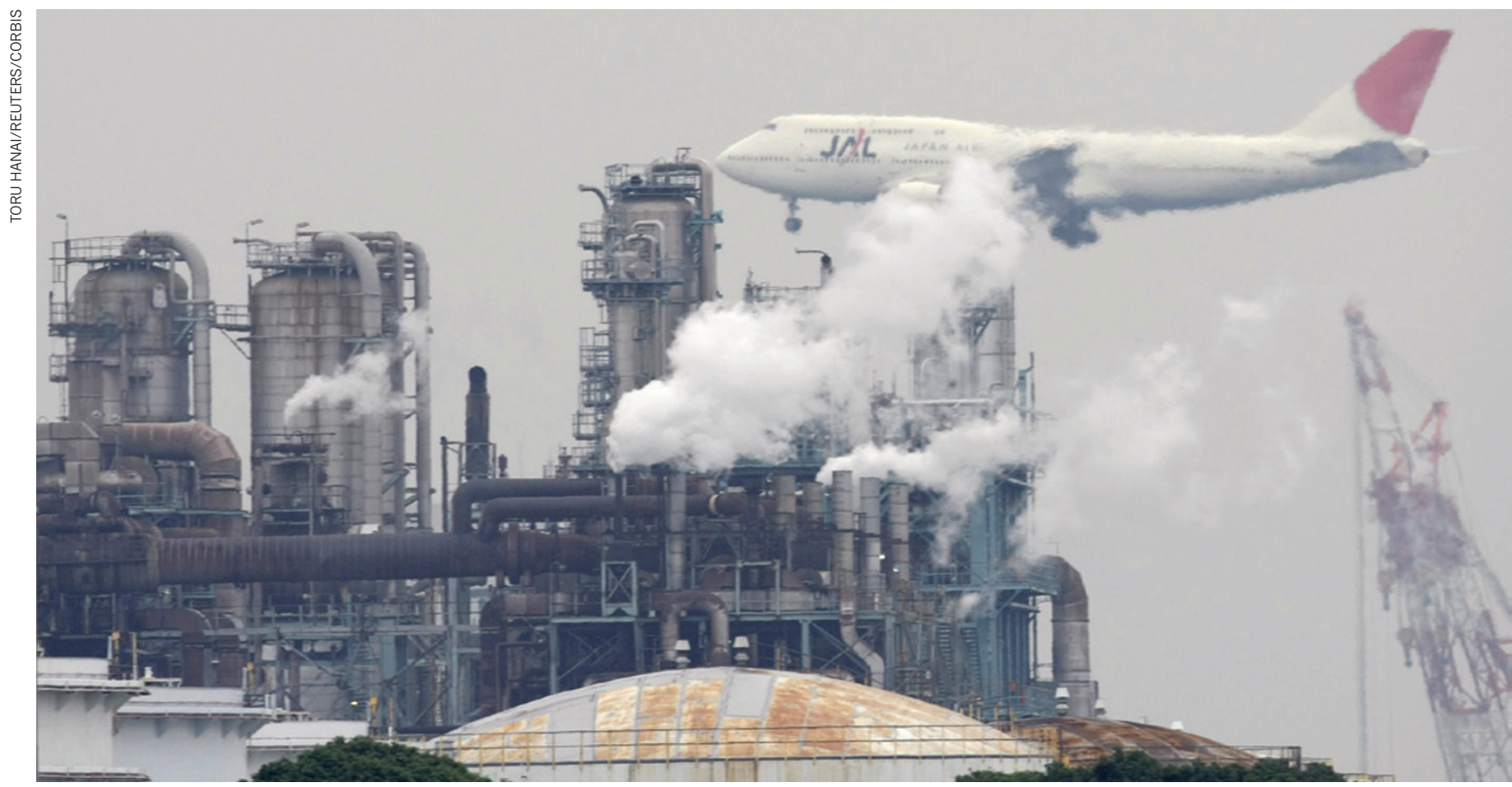

Carbon markets tackle factory emissions in many nations around the world; the European Union is now looking to include non-EU aviation.

\section{Carbon trading needs a multi-level approach}

\section{International agreements are not enough. Interlinked national and regional tools are} also needed to reduce carbon emissions, say Mark Maslin and Joanne Scott.

$\mathrm{C}$ arbon emissions rose to an all-time high in 2010, and international negotiations to agree binding national carbon-emissions targets have so far failed. However, intergovernmental failings have not slowed the expansion of trading in carbon emissions.

Carbon markets are being set up at multiple levels of governance - including locally, regionally and supranationally. Markets have been set up in the European Union (EU) and New Zealand, and plans are afoot for markets in California, Australia and India. The biggest by far, the European Union's Emissions Trading Scheme (ETS), is using its carbon market power to experiment with new solutions to old problems, and to spur climate action elsewhere.

Controversially, the ETS is set to extend its carbon market to include some non-EU emissions. For example, from 2012, the ETS could cover emissions amounting to almost $60 \%$ of the world's international commercial aviation emissions. Although this move is being challenged in the courts, the EU claims that it is already encouraging the
United Nations International Civil Aviation Organization to consider a global regime for aviation emissions. Similarly, the EU is using the threat of further ETS expansion to galvanize global carbon regulation of maritime transport.

Such overlapping, interacting regulatory frameworks have many advantages. They offer multiple opportunities to learn which regulations are most effective in the short and long term. Local efforts also build redundancy into the system: they act as regulatory safety nets if higher-level 
negotiations break down. And, as shown by the EU, local action can help to shape the dynamics of international negotiations. Critics fear multiple bureaucracies that are messy and confusing, and which introduce high transaction costs, but although a top-down system of governance may be neat, such an effort would be unlikely to succeed.

\section{THE RISE OF INTELLIGENCE}

Trading in carbon emissions has created a major global market since the mid 1990s, with an estimated spend of US $\$ 142$ billion in 2010, of which $85 \%$ was through the ETS ${ }^{1}$. Another $\$ 48$ billion was spent in $2009-10^{2}$ solely on carbon-market intelligence (gathering and analysing information required for the effective sale or purchase of carbon-based credits). The size of the carbon-emissions market itself was essentially unchanged between 2009 and 2010, despite the economic recession (see 'The size of the carbon market'). At the same time, businesses and governments have been increasingly investing in efforts to understand the flow of carbon, in order to plan economic and environmental strategies. Updated figures compiled for this article by UK-based consultancy kMatrix show that the intelligence sector has grown again in $2010-11$, to $\$ 56$ billion, a growth of $16 \%$ in a single year (see 'The size of the carbon market'). The quality and usefulness of this information varies enormously, but its growth underscores the importance of reliable carbon data in understanding the development of this potentially huge market.

The bulk of the carbon-emissions market is made up of trading in carbon allowances in 'cap-and-trade' systems. These markets are usually national and regional because it is easier to set a cap on emissions within borders and in relation to particular industries. At the international level, carbon markets trade in credits from certified projects under the Kyoto Protocol's Clean Development Mechanism (CDM). The CDM allows investors, such as companies and countries, to purchase carbon offsets known as Certified Emission Reductions by investing in carbon-reduction projects in developing countries. For example, the carbon credits from the emissions saved as a result of the construction of a wind farm in India can be bought by an EU power company to meet its emissions-reduction obligations under the ETS.

Assessing - monitoring, recording and verifying - the quality and quantity of carbon emissions 'saved' has long been a problem for the CDM. For example, credits for projects involving the capture of industrial gases (hydrofluorocarbons or HFCs) have been regrettably easy to game. The regulation has created a perverse incentive for companies to produce more HCFC-22, a refrigerant and powerful greenhouse gas being phased

out under the Montreal Protocol, in return for windfall profits for capturing the HFC-23 by-product from its production ${ }^{3}$. About $70 \%$ of Certified Emission Reductions have come from projects of this kind. Depressingly, the European Commission concluded this year that production of HCFC-22 could be higher today than it would have been in the absence of CDM activity.

The problem with industrial gas credits has been known since at least 2007, yet the multinational executive board that supervises the CDM has been unable to reach an agreement on how to solve it. So far, only a partial and provisional ban on gas-capture projects has been agreed. Happily, the EU does not rely exclusively on

\section{"The EU has lost patience with international regulators."} international regulation of the CDM. Having finally lost patience with international regulators, it will ban the use of credits from industrial gas projects in the ETS from 2013.

The industrial gases saga has highlighted other failings of the CDM. Perhaps the hardest problem for carbon offsets concerns 'additionality'. In principle, Certified Emission Reductions come from projects that create emissions reductions that are 'additional' to those that would otherwise have been achieved. Verifying additionality by reference to a baseline, which rests on a business-as-usual assessment (the level of carbon emissions if this project had not been put in place) has proved very difficult. As a result, there are doubts about the CDM's ability to bring about genuine emissions reductions.

One solution to the additionality problem may come from the EU push into sectoral carbon trading. A 'sectoral' approach to emissions would fundamentally change the way in which the EU measures emissions saved as a result of CDM projects. Additionality would no longer be assessed by reference to a hypothetical business-as-usual baseline, but by reference to sector-by-sector carbonefficiency standards. To generate credits, a project would have to cut emissions below the level of 'mere' compliance with the standard. In the absence of global agreement, the EU is seeking bilateral agreements to move forward with this approach, and is threatening to refuse Certified Emission Reductions from new projects after 2013 - except those based in least-developed countries - to persuade countries to come on board.

The EU is also extending the geographical reach of the ETS. From 2012, all flights arriving in or departing from an EU airport will be required to surrender an emissions allowance or certificate for each tonne of carbon emitted during flight, including those occurring outside EU airspace (unless those emissions are subject to climate regulation elsewhere). By 2020, the ETS could add an estimated \$11-56 to a return long-haul flight. At first, $85 \%$ of these certificates will

\section{THE SIZE OF THE CARBON MARKET} Carbon-emissions trading was growing fast until it stalled when global recession hit in late 2008.
But spend on market-intelligence activities, from project development to carbon accounting, grew by $16 \%$ between $2009-10$ and $2010-11$.

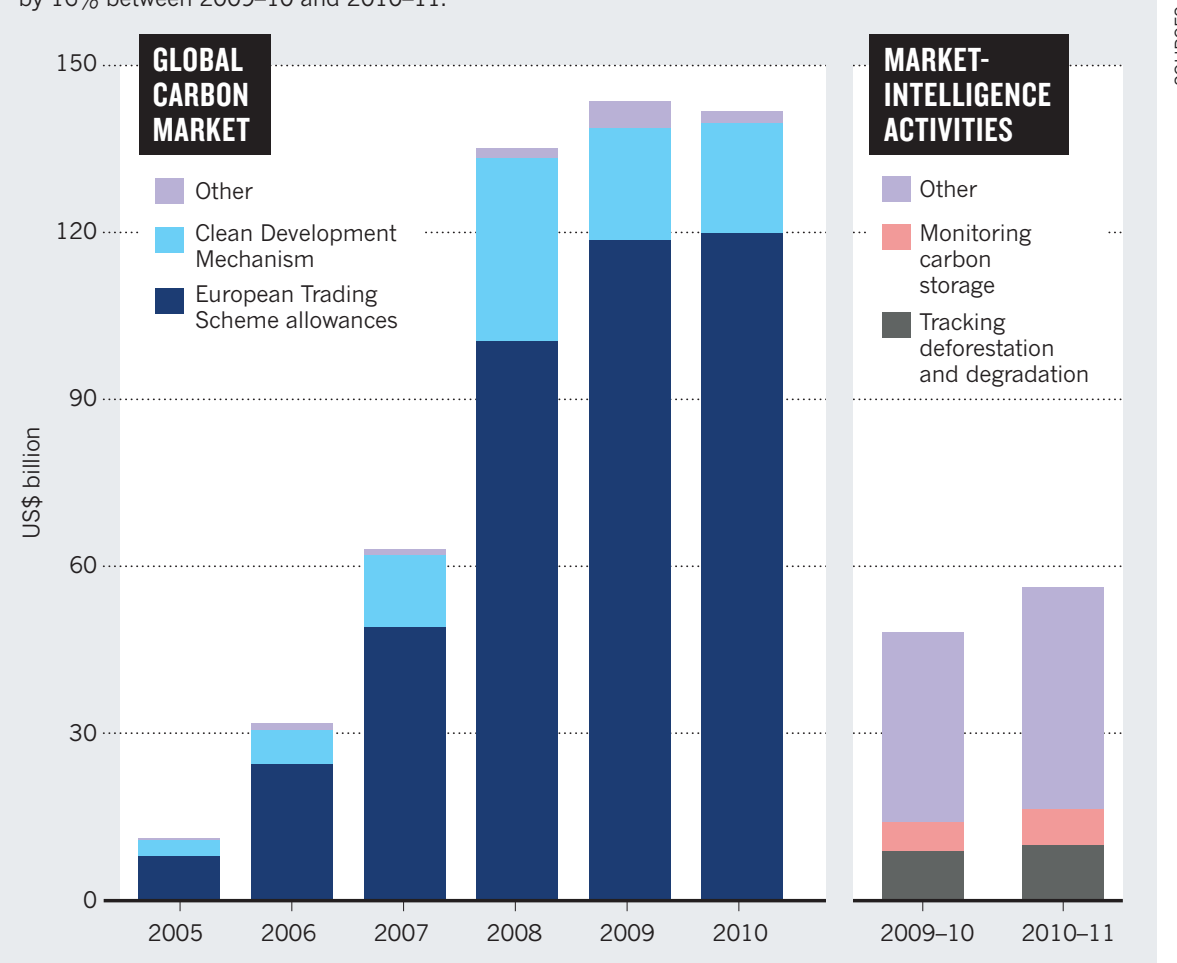


be issued by the EU free of charge, with the airlines buying the remaining 15\% at auction. These rules are being challenged by the major US airlines in a case currently before the EU's highest court. A final judgment is expected in the first half of 2012.

Policy-makers need examples of good practice or good ideas. The International Carbon Action Partnership - a group of countries and regions that are pursuing capand-trade systems - is intended to share knowledge and experience on the development of carbon markets. Similarly, Sandbag, a London-based non-governmental organization, submitted comments in 2010 on California's plans to establish a cap-andtrade system, which drew heavily on the good, the bad and the ugly of European experience with the ETS.

\section{IF NO ONE HEARS A TREE FALL}

Lessons from the ETS experience with the CDM should be applied to the design and operation of the UN programme for Reducing Emissions from Deforestation and Forest Degradation in Developing Countries (REDD+). Although there is debate about the share of global carbon emissions that may be attributed to deforestation and landuse change, a figure of around $20 \%$ is often put forward ${ }^{4}$. Without proper oversight at multiple levels of governance, as with the CDM there will be real difficulties in assessing the quantity and quality of the carbon emissions 'saved'.

Following the UN climate negotiations in Copenhagen in 2010, developed countries made non-binding pledges to reduce emissions by between $13 \%$ and $19 \%$ (compared with a 1990 baseline $)^{5}$. The EU has made a binding commitment to reduce emissions by $20 \%$ by 2020 (again compared with a 1990 baseline). If carbon allowances or offsets from REDD+ were available for use in achieving compliance with these targets, the need, worldwide, for meaningful domestic cuts would cease. Hence, it is crucial that there are robust ceilings on the use of REDD+ credits in domestic carbon markets, if incentives for national action are to remain meaningful.

It is also essential that the projects funded do not generate adverse social, cultural or environmental effects. Investors in REDD+ and governments that permit REDD+ allowances to be used for compliance must share responsibility with host governments for developing and improving project assessments to avoid negative effects. There are also worries that REDD+ underestimates implementation costs and could undermine good forest governance programmes in key countries ${ }^{6}$.

Again, the biggest and most intractable problem is additionality. Although $47 \%$ of anthropogenic carbon emissions remain in the atmosphere, $27 \%$ are absorbed by the

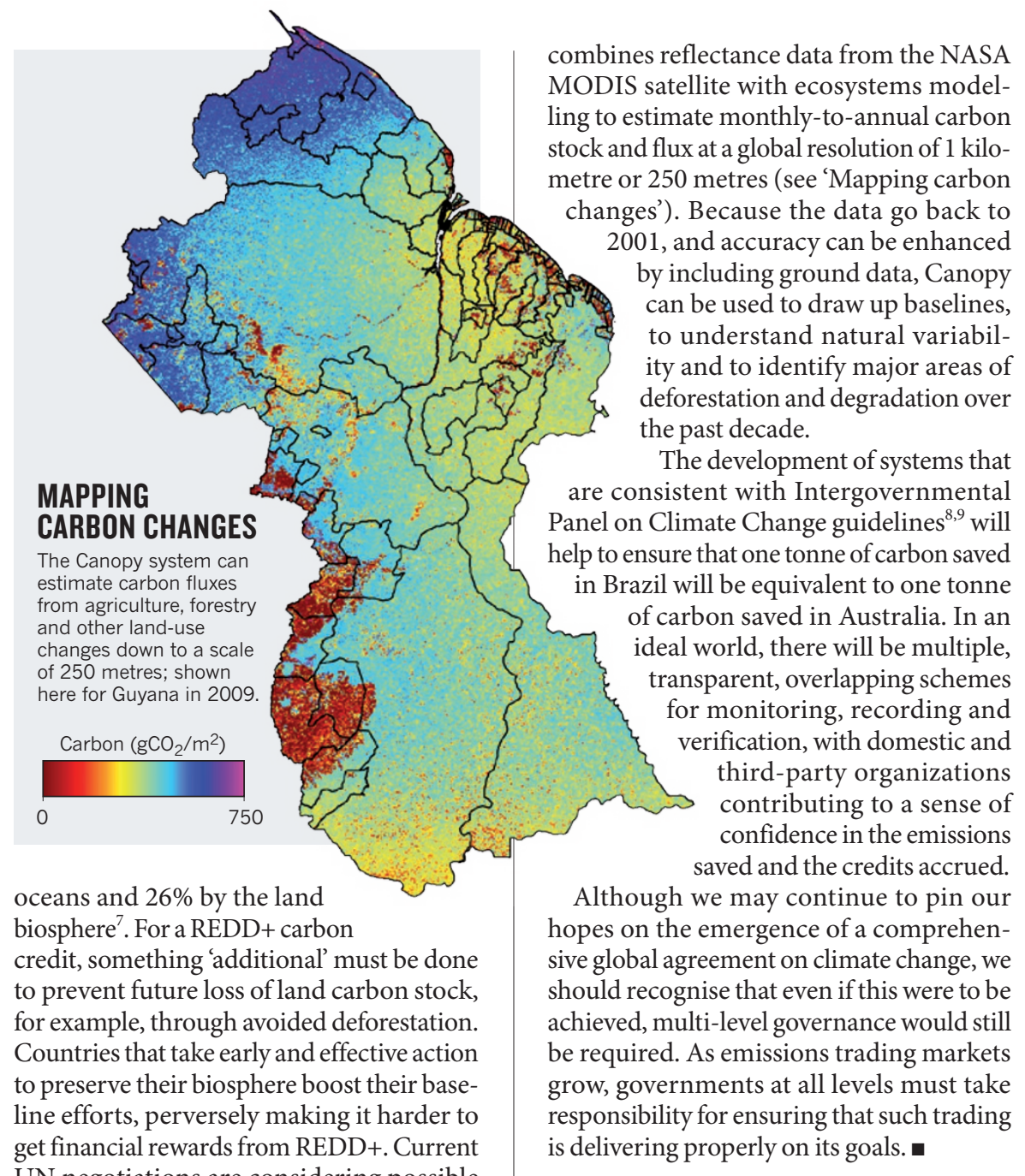
UN negotiations are considering possible ways of addressing this problem, including setting a regional deforestation rate, which would serve as a baseline for all countries in a given region, regardless of their actual or projected rate of deforestation.

The multiple challenges of REDD+ will not be solved by the UN alone. Until recently, measuring the change in land carbon stock and annual flux was thought to be 'beyond science', because only static data sets for the early 2000 s were available ${ }^{4}$. Despite this, a staggering $\$ 6.3$ billion was spent in 2010-11 (a 20\% increase on the previous year) on monitoring land carbon, with the quality of data often being extremely poor. The lack of verifiable data for REDD+ has the potential to undermine the whole programme by making it easy to cheat. However, considerable scientific progress is being made and new methods for verifying data are emerging.

One of us (M.M.) is involved in such an approach. Work by Carbon Auditors, a London-based company spun out from University College London, in partnership with business service company Logica, shows that monitoring, recording and verification can be done effectively using their jointly developed 'Canopy' system. Canopy
Mark Maslin is in the Department of Geography, University College London, Pearson Building, Gower Street, London WC1E 6BT, UK. Joanne Scott is in the Faculty of Laws, University College London, Bentham House, Endsleigh Gardens, London WC1H OEG, UK. e-mail:mmaslin@geog.ucl.ac.uk

1. Linacre, N. et al. State and Trends of the Carbon Market 2011 (World Bank, 2011); available at: go.nature.com/xveyp4

2. Poessinouw, M. \& Howard, S. Knowledge Matrix Limited Carbon Market Intelligence Report for Carbon Auditors Limited (2010).

3. Wara, M. Nature 445, 595-596 (2007)

4. Saatchi, S. S. et al. Proc. Natl Acad. Sci. USA 108, 9899-9904 (2011).

5. Levin, K. \& Bradley, R. Comparability of Annex I Emission Reduction Pledges. Working Paper (World Resources Institute, 2010); available at go.nature.com/m7uipe

6. Phelps, J., Webb, E. L. \& Agrawal, A. Science $\mathbf{3 2 8}$ 312-313 (2010).

7. Friedlingstein, P. et al. Nature Geosci. 3, 811-812 (2010).

8. Penman, J. et al. (eds) Good Practice Guidance for Land Use, Land-Use Change and Forestry (IPCC, 2003).

9. Eggleston, S. et al. (eds) 2006 IPCC Guidelines for National Greenhouse Gas Inventories. Volume $4-$ Agriculture, Forestry and Other Land Use (IPCC, 2006).

The authors declare competing financial interests: for details see go.nature.com/h8k4dk 